\title{
Child Abuse and Neglect: Sharing Responsibility
}

By Pamela D. Mavhall and Katherine Eastack Norgard.

New York: John Wiley and Sons, 1983, 389 + xir pp.. \$1+.tj (paperback).

Child Abuse and Veglect: Sharing Responsibility appears to be a comprehensive text for a course on child maltreatment. The first three chapters place child maltreatment in context, chapter 1 explicating its role historically. chapter 2 discussing family functions and violence within the family, and chapter 3 addressing developmental stages and the impact of maltreatment on child development. In the fourth chapter. the authors grapple with the problems of definition of child maltreacment and with the complex issue of incidence rates, and then turn briefly to the impact of child maltreatment upon its victims. The next four chapters deal separately with phvsical abuse, physical neglect, emotional maltreatment, and sexual abuse. In each of these chapters the authors present information on the prevalence of the type of maltreatment, a definition. indicators. sub-categories of the type of maltreatment, in some instances information on its characteristics at different developmental stages, and theories about calusality of the particular type of maltreatment. The remaining chapters in the book focus upon intervention. Chapter 9 discusses the various professional actors and their perspectives: child protective services, law enforcement, medical services. the juvenile or family court, the criminal justice system, public and private service agencies. community child care programs, and self-help groups. Chapter 10 describes in detail the formal response of child protective services to suspected child abuse and neglect. Chapter 11 is a discussion of legal intervention and the court process. In chapter 12, resources available to improve family functioning, including health care, day care, employment. financial assistance, and various outreach services, are explained. Chapter 13 is a discussion of treatment, and chapter 14 is a concluding chapter entitled "Child Abuse and Neglect: Sharing Responsibility." There are five appendices. These are: appendix 1: "Intervention and Protection of Children: A Historical Perspective": appendix 2: "Jess: A Case Study"; appendix 3: "The Care and Feeding of a Child Protection Team": appendix 4: "Improving Your Skill in Interviewing"; and appendix 5: "Helpful Hints for Witnesses."

This book has both strengths and weaknesses. It is impressive in its comprehensiveness. It deals with a great many aspects of the problem of child maltreatment from the standpoint of a human services worker. The authors include material on child development, on interviewing, on the family as a system and on court testimony, as well as information specifically on child abuse and neglect. They provide a useful historical outline in appendix 1 for reference and they make appropriate use of case examples. Of particular value is their update of the content of state child protection systems which appears in chapter 4 . The authors have gone to a great deal of trouble not only in acquainting themselves with much of the literature on child abuse and neglect but also in interviewing or otherwise personally communicating with professionals involved in the field. 
A second strength of the book is its clear explication of the formal intervention and case management aspects of child abuse and neglect. Chapters 9 and 10 are in the writer's opinion the best chapters in the book. These chapters demonstrate the authors have first-hand knowledge of the perspectives of the range of professionals likely to be involved with child maltreatment and of the details of the Child Protective Services response to cases.

The third strength of the book is that the authors separately address different types of child maltreatment they have chosen to discuss. Ther avoid making the assumption made by too manv witers that child maltreatment is a single entity with a unitary set of dynamics. They also in part describe subcategories of each of the four types of maltreatment. In the writer's opinion, there are many types of maltreatment, each with subcategories, and the focus of knowledge development should be on developing our understanding of these subcategories. While the authors have made considerable headway in this area, it should be riewed as a beginning effort. There are other types of child maltreatment that should be singled out and dealt with as separate entities, non-organic growth fature and burns, for example. Further, while the authors present explanations of the dynamics for each of the four types, these are not well integrated. Rather, they offer a kind of smorgasbord of explanations without much attempt to be critical about the theories or to develop a conceptual framework to help the reader understand why a particular wpe of child maltreatment may occur. Finally, each of these types of maltreatment should be addressed with distinct forms of intervention, but the authors do not carry their discussion into this arena.

The book has other shortcomings. The major one is that some parts of the book are well written and others are not. It appears that one of the authors writes clearly and the other does not. The poorly written parts are very frustrating to read because they are badly organized, headings and subheadings do not convey to the reader the content of the sections, expression of ideas is so imprecise and syntactically awkward that the reader is left confused, and often subjects and predicates do not agree. One of the authors appears to know that the noun, data, is plural while the other does not. These shortcomings in writing ability detract measurably from the usefulness of the book.

In part, these problems also bespeak a poor job of editing. There are other indications of poor editing. There are quite a number of typographical errors; there are authors names and book titles misspelled or misquoted; layout and formating changes mid-chapter; and citation conventions are inconsistent. In addition, there are many places where the authors make assertions that should be supported by citation but are not.

In general, the best chapters of this book are the ones dealing with the professional response and systemic intervention. Weaker chapters are those dealing with the dynamics of child maltreatment and treatment. The book would be quite useful for persons entering the child welfare field as child protection or court workers. It also would assist the mental health professional or the physician who needs to understand the re- 
sponse of mandated agencies to child maltreatment. It does not provide adequate guidelines to serve as a major resource for mental health treatment planning. While the authors assert in their preface that thet view child abuse and neglect as everyone's responsibility, and subtitle the book "Sharing Responsibility," little attention is paid to this contention in the book. It is not, in fact, a book for everyone who should shate responsibility. but rather for select professionals who have considerable responsibility for addressing this very difficult problem.

Kathleen Coulborn Faller University of . Hichigan

\section{The Long Struggle: Well Functioning Working Class Black Families.}

By Jerry M. Lewis and John C. Looney.

New York: Brunner/Mazel. 1983, 193 + x pp., \$25.00) (hardcover).

The black family is controversial. Its status has been heatedly debated in a dispute that can scarcely have escaped the reader's attention. On one side are those who view the black family as a "tangle of pathology," to use Daniel Patrick Moynihan's often-cited, provocative phrase: on the other side are those who argue that pathology has been overstated. strengths overlooked, and racism ignored.

There are reasons to believe, however, that extreme polarization of views has slackened. Many blacks now openly acknowledge that the black family indeed may be in trouble. Simple demographic trends tell an alarming story: In 1982, 46.5\% of black families were headed by women. up from $30.6 \%$ in 1970, and a mere $8.3 \%$ in 1950. The figure for white families headed by females is consistently less than one third that for black families. Some worry about the psychological consequences for children of this phenomenon, while others minimize or deny such consequences. Everyone agrees, however, on economics: Women earn much less than men, and as a result, a shocking number of black women and their children live in poverty. Then again. not all black families are casualties. Even among those suffering the greatest hardship. some successfully provide an orderly and supportive environment for their members. In all likelihood. this often is clone in ways that break with tradition and are hidden from standard methods of assessment. How can real problems be recognized and real assets enhanced?

This is the context of issues for a book like the present one, titled The Long Struggle: Well Functioning Working Class Black Families. The title and publicity for this book raise high expectations; unfortunately, they are satisfied only to a modest degree. But even small inroads are welcome in solving a problem as vexing and urgent as how to understand lowincome black families. 